Postprint of Journal of the American Oil Chemists' Society December 2015, Volume 92, Issue 11, pp 1601-1607

doi: 10.1007/s11746-015-2724-2

\title{
New analytical evidence of discontinuous oxidation in dried microencapsulated lipids
}

Arturo Morales ${ }^{1}$, Susana Marmesat ${ }^{1}, \mathrm{M}^{\mathrm{a}}$ Victoria Ruiz-Méndez ${ }^{1}$, Gloria Márquez-Ruiz ${ }^{2}$ and Joaquín Velasco ${ }^{1, *}$

${ }^{1}$ Instituto de la Grasa, Consejo Superior de Investigaciones Cientificas (CSIC),

Campus Universidad Pablo de Olavide E46, Ctra. de Utrera km 1, E-41013 Sevilla, Spain

${ }^{2}$ Instituto de Ciencia y Tecnología de Alimentos y Nutrición, Consejo Superior de Investigaciones Cientificas (CSIC), c/ José Antonio Novais, 10, E-28040 Madrid, Spain

*To whom correspondence should be addressed:

Telephone: $\quad+34954611550$

Fax: +34954616790

E-mail: jvelasco@ig.csic.es 


\section{$1 \quad$ Abstract}

2 Formation of hydroperoxy-, keto- and hydroxy- dienes was studied at $40{ }^{\circ} \mathrm{C}$ in fatty acid

3 methyl esters (FAME) microencapsulated in a dairy-like matrix formed by lactose and

4 sodium caseinate. The FAME were obtained from conventional sunflower oil and the

5 microcapsules were prepared by freeze-drying of an oil-in-water emulsion. For

6 comparative purposes a neat sample of FAME was also tested. Results showed that for a

7 given content of hydroperoxydienes much more elevated amounts of secondary

8 products were detected in the microencapsulated sample compared to the neat sample of

9 FAME. The contents of keto- and hydroxy- dienes found in the microencapsulated

10 FAME ranged as a whole between 6 and $31 \mathrm{wt} \%$ of the analyzed compounds, while the

11 neat sample showed values lower than $1.5 \%$. Along with the fact that relatively higher

12 contents of polymers were also found in the encapsulated sample, these results can be

13 attributed to lipid droplets with very different oxidation states. On the one hand, the

14 extract would be formed from droplets in early stages of oxidation containing

15 hydroperoxides and very low contents of secondary products and, on the other, from

16 droplets in advanced stages with decreased hydroperoxides and substantial contents of

17 secondary products. Unlike the neat sample, hydroxydienes formed at significantly

18 higher amounts than ketodienes in the microencapsulated FAME, suggesting a possible

19 chemical role of the encapsulation matrix.

20 Key-words: Hydroperoxides, ketodienes, hydroxydienes, autoxidation, 21 microencapsulation 


\section{Introduction}

24 Dehydration of oil-in-water emulsions containing proteins and/or carbohydrates is a common process in the manufacture of food powders. Today there are a number of formulated food emulsions that are dehydrated such as infant formulae and emulsions containing polyunsaturated lipids or oils as a carrier of flavours, vitamins and other components [1-3]. The oil in these products is encapsulated as a disperse phase in the inner of solid particles that act as a physical barrier protecting it against oxidation.

Evaluation and control of lipid oxidation in microencapsulated lipids is of great significance because it results in the development of objectionable flavors and formation of compounds that may be detrimental to health [4]. The oxidation in these products is quite complex because droplets may oxidize at different rates and have very different oxidation states when the lipid extract is analyzed. Oxidized droplets may occur in the presence of others well protected by the encapsulation matrix. Even when the global content of oxidation products is low due to the oxidation of a minor fraction, complex mixtures of primary, secondary and even advanced oxidation compounds may be detected in quite different proportions to that of a sample of oil in continuous phase with the same total content of oxidation products [5]. It is therefore evident that evaluation of oxidation in such cases would not be possible with the methods of analysis normally applied in labs of quality control, based upon analytical indices such as the peroxide value.

In previous studies carried out in our lab, quantitative analysis of the main oxidation

44 products of linoleic acid, i.e. hydroperoxy-, keto- and hydroxy- dienes, has been 45 developed to analyze directly oxidized samples of fatty acid methyl esters (FAME) 46 derived from vegetable oils. The separation and detection of analytes was based upon 47 the NP-HPLC-UV analysis proposed by Hopia, Huang, \& Frankel [6] to evaluate 
oxidized samples of methyl linoleate. The conjugated diene structure of methyl linoleate hydroperoxides and hydroxides can be readily detected by absorption of UV light at 232-234 nm, depending on the polarity of the solvent, while that of methyl linoleate ketones are detected at 268-270 $\mathrm{nm}$ [7-8]. The method was then adapted to the analysis of real samples of vegetable oils by applying an adequate derivatization step to transform the oxidized triacylglycerol (TAG) molecules into FAME [9].

Compared to the analytical indices commonly applied to evaluate lipid oxidation, the main advantage of this method is that allows quantitation of compounds and the simultaneous determination of primary oxidation compounds, hydroperoxides, and their principal secondary products, keto- and hydroxy- compounds, in low amounts. In this regard, the quantification of lipid oxidation products in foods constitutes a starting point to determine if the contents in the diet are sufficient to have a role in a variety of chronic diseases, such as cardiovascular diseases and cancer. Oxidized lipids are known to be involved in such diseases, but the real contribution of lipids coming from the diet is unknown because the contents of oxidation products in foods have not been established due to their analytical complexity [10].

The method has only been applied to the analysis of pure FAME, FAME obtained from oils, and vegetable oils that were all oxidized in continuous phase [6-9, 11-12].

In this work we study the quantitative formation of hydroperoxy-, keto- and hydroxydienes in FAME microencapsulated in a dairy-like matrix formed by lactose and sodium caseinate [5]. The FAME were obtained from conventional sunflower oil and the microcapsules were prepared by freeze-drying of an oil-in-water emulsion containing 10 wt $\%$ FAME, $10 \mathrm{wt} \%$ sodium caseinate, $10 \mathrm{wt} \%$ lactose and $70 \mathrm{wt} \%$ water. The water

71 activity and the glass transition temperature were measured along the oxidation study to examine possible changes of the particle structure. Although the microencapsulated 
73 sample under study can be considered a model system of microencapsulated oils or even

74 of powdered infant formulae, it should be noted that ethyl esters of polyunsaturated 75 fatty acids are microencapsulated and marketed as dietetic supplements or ingredients to 76 supplement foods with functional lipids. The analyses were performed in the free and 77 encapsulated lipid fractions of the microencapsulated FAME. For comparative purposes 78 formation of the compounds was also studied in neat FAME. In addition to the HPLC 79 method, the analysis of polymers by high-performance size-exclusion chromatography 80 with refractive-index detection (HPSEC-RI) was also performed to evaluate advanced 81 oxidation products. 
84 Chemicals

Sodium caseinate and D-lactose monohydrate were purchased from Sigma-Aldrich

Química S.A. (Madrid, Spain). Diethyl ether stabilized with 1\% v/v ethanol (Super

87 purity solvent, HPLC grade) was purchased from Romil, LTD (Cambridge, UK) and n-

88 heptane (99\% purity, HPLC grade) from Carlo Erba Reactifs-SDS (Val de Reuil,

89 France). Both HPLC solvents were used as received.

90 Samples

91 FAME were obtained from refined high linoleic sunflower oil by transmethylation with

$92 \mathrm{KOH}$ in methanol according to a previous report [11]. The oil was supplied by Koipe

93 S.A. (Andújar, Jaén, Spain). The fatty acid composition was determined to be $6.7 \%$

$94 \mathrm{C} 16: 0,0.2 \% \mathrm{C} 16: 1,3.6 \% \mathrm{C} 18: 0,33.0 \% \mathrm{C} 18: 1,55.2 \% \mathrm{C} 18: 2$ and $1.3 \%$ others.

The FAME were encapsulated in a matrix of sodium caseinate and D-lactose according to a previous report [13]. An o/w emulsion was prepared from the FAME and a solution

97 containing the encapsulating components. The weight composition of the emulsion was 10\% FAME, $10 \%$ sodium caseinate, $10 \%$ D-lactose and $70 \%$ water. A coarse emulsion was prepared in an Ultraturrax DI-25 (IKA, Germany) by applying $454 \mathrm{~g}$ for $2 \mathrm{~min}, 641$ $\mathrm{g}$ for $2 \mathrm{~min}$ and $1294 \mathrm{~g}$ for $1 \mathrm{~min}$. The emulsion was refined in an EmulsiFlex-C5

101 (Avestin Inc., Canada) high pressure homogenizer by applying $70 \mathrm{MPa}$ and two passes.

102 The emulsion was frozen $-32{ }^{\circ} \mathrm{C}$ for $24 \mathrm{~h}$ and freeze-dried in a lab-scale Heto FD3 freeze-dryer (Allerød, Denmark) for $48 \mathrm{~h}$. Finally, in batches of $20 \mathrm{~g}$ the dried emulsion was ground in a domestic electronic coffee grinder of $400 \mathrm{~mL}$ volume for $10 \mathrm{~s}$ at interval of $5 \mathrm{~s}$ and a homogenous powder product was obtained. 
107 A neat sample of FAME was oxidized in a beaker at $40^{\circ} \mathrm{C}$ in the dark by using an oven

108 with continuous air circulation. The surface-to-volume ratio of the FAME sample was

109 as high as $5 \mathrm{~cm}^{-1}$ so that oxidation was developed under non-limited oxygen conditions.

110 Three aliquots of $100 \mathrm{mg}$ each were sampled periodically in a period of 7 days.

111 Independent 10 -g samples of dried microencapsulated FAME were oxidized at $40{ }^{\circ} \mathrm{C}$ in

112 closed amber bottles of $250 \mathrm{~mL}$. An assay tube with $10 \mathrm{~mL}$ of a saturated solution of

113 potassium acetate was placed into each bottle to create an atmosphere of $23 \%$ relative

114 humidity [14]. Periodic samplings were performed in a period of 12 days. Three bottles

115 were drawn from the oven in each sampling and the samples were kept at $-25^{\circ} \mathrm{C}$ until

116 analysis.

117 Analyses of intact dried microencapsulated samples

118 Water activity

119 The water activity of the microencapsulated samples was measured using a PawKit

120 hygrometer (Decagon Devices Inc., Pullman, WA, USA).

121 Glass transition temperature

122 The glass transition temperature $\left(\mathrm{T}_{\mathrm{g}}\right)$ of the microencapsulated FAME was determined

123 using a DSC Q 2000 calorimeter (TA Instruments, New Castle, DE, USA) according to

124 a previous report [13].

125 Lipid extraction from the microencapsulated samples 
126 The free lipid fraction was extracted according to Sankarikutty, Sreekumar, Narayanan,

$127 \&$ Mathew [15]. A volume of $100 \mathrm{~mL}$ of $\mathrm{n}$-hexane was added to $10 \mathrm{-g}$ sample and

128 stirring was applied at room temperature for $15 \mathrm{~min}$. The solvent was filtered through a

129 filter paper and evaporated in a rotary evaporator at $40{ }^{\circ} \mathrm{C}$. The extract was dried to

130 constant weight using a stream of nitrogen. The treated powder was left in a fume

131 cupboard until the complete loss of trace hexane.

132 The encapsulated lipid fraction was extracted with dichloromethane and methanol (2:1, $133 \mathrm{v} / \mathrm{v}$ ) in the absence of water according to a previous report [16]. In brief, a $75 \mathrm{~mL}$ 134 volume of dichloromethane followed by a $35 \mathrm{~mL}$ volume of methanol was added to the

135 sample. The mixture was vigorously stirred in a magnetic stirrer at room temperature for $13630 \mathrm{~min}$. The solvent was filtered through a filter paper and evaporated at $40{ }^{\circ} \mathrm{C}$ in a 137 rotary evaporator. The extract was finally dried to constant weight using a stream of 138 nitrogen.

139 Analysis of FAME

140 Analysis by HPLC

141 The main oxidation products of methyl linoleate, i.e. hydroperoxy-, keto- and hydroxy142 dienes, were determined quantitatively by an HPLC-UV method developed by our lab

143 [7]. A Waters 600 HPLC chromatograph (Waters Corp., Milford, MA, USA) equiped 144 with a 600 Waters pump, a Rheodyne injector valve (20- $\mu \mathrm{L}$ sample loop), a silica

145 HPLC column (LiChrospher ${ }^{\circledR}$ Si 60, $250 \mathrm{~mm} \mathrm{x} 4 \mathrm{~mm}$ i.d., $5 \mu \mathrm{m}$ particle size) (Merck,

146 Darmstadt, Germany), an HP 1050 Series variable wavelength UV detector (8 mm path

147 length) (Agilent Technologies Inc., Palo Alto, CA) and a 600 Waters controller was 148 used. The separation of analytes was performed in isocratic elution using n- 
149 heptane:diethyl ether $(82: 18, \mathrm{v} / \mathrm{v})$ with a flow rate of $1 \mathrm{~mL} / \mathrm{min}$. Ethanol present in the

150 diethyl ether as a stabilizer was not removed. Hydroperoxy- and hydroxy- dienes were

151 recorded by the UV detector at $234 \mathrm{~nm}$, while ketodienes were at $268 \mathrm{~nm}$. The FAME

152 samples both neat and extracted were dissolved in $\mathrm{n}$-hexane in a range of $1-50 \mathrm{mg} / \mathrm{mL}$

153 prior to analysis. Quantitative data were obtained by applying response factors reported

154 elsewhere [7].

155 Analysis of polymers

156 Analysis of polymers was performed according to IUPAC standard method 2.508 [17]. An

157 HPSEC chromatograph equipped with a Rheodyne $7725 \mathrm{i}$ injector with a $10-\mu \mathrm{L}$ sample

158 loop, a Knauer 120 HPLC pump (Knauer, Berlin, Germany) and a Merck L-7490

159 refractive index detector (Merck, Darmstadt, Germany) was used. The separation was

160 performed on two 100 and $500 \AA$ Ultrastyragel columns ( $25 \mathrm{~cm} \mathrm{x} 0.77 \mathrm{~cm}$ i.d.) packed

161 with porous, highly cross-linked styrene-divinylbenzene copolymers $(5 \mu \mathrm{m})$ (Agilent

162 Technologies, Palo Alto, CA) connected in series by using tetrahydrofuran as the

163 mobile phase at a flow rate of $1 \mathrm{~mL} / \mathrm{min}$.

164 Statistical analysis

165 Analytical determinations were carried out in triplicate and results were presented as

166 mean values. Comparisons were made by the Student's $t$ test in Microsoft Excel 2010

167 (Microsoft Corporation, Redmond, WA, USA). Significance was defined at $p<0.05$. 
170 The amounts of the free and encapsulated lipid fractions extracted, the water activity

171 and the glass transition temperature $\left(\mathrm{T}_{\mathrm{g}}\right)$ of the microencapsulated samples showed no

172 substantial changes along the oxidation study. The amounts of lipids were 6-9 $\mathrm{g} / 100 \mathrm{~g}$

173 sample for the free lipid fraction and 15-19 $\mathrm{g} / 100 \mathrm{~g}$ of sample devoid of free oil for the

174 encapsulated fraction. The water activity showed values of $0.20-0.27$ and the $T_{g}$ of $45-$

$17547^{\circ} \mathrm{C}$. It can be said that the structure of the powder particles remained without

176 significant changes that resulted in changes in the amounts of the free and encapsulated

177 lipid fractions during the study. The fact that the oxidation temperature was lower than

178 the $\mathrm{T}_{\mathrm{g}}$ in just $5-7^{\circ} \mathrm{C}$ seemed to be sufficient so as not to occur such structural

179 modifications [18]. Structural changes of the microencapsulation matrix can give rise to

180 changes in the lipid distribution. Thus, an increase in the content of the free lipid

181 fraction due to lactose crystallization is a well-known phenomenon in milk powder and

182 dairy-like microencapsulated lipids $[19,20]$. Absorption of water, storage temperature

183 and storage time decrease the viscosity of the amorphous matrix allowing

184 reorganization of its molecules $[18,19]$.

185 HPLC analysis showed that the chromatograms of the lipid extracts of the

186 microencapsulated FAME were not different from those of the neat sample in terms of

187 occurrence of new peaks or changes in the distribution of isomers in each group of 188 compounds (Fig. 1).

189 As expected, oxidation was quicker in the continuous system. The hydroperoxides

190 showed a period of slow formation followed by another of acceleration in both systems.

191 Keto- and hydroxy- dienes displayed a similar pattern to that of hydroperoxides (Fig. 2).

192 The substantial increase of hydroperoxides occurred at 4 days in the neat sample and at 
1938 days in both the free and encapsulated fractions of the microencapsulated sample. The

194 formation of hydroperoxides in the accelerated period was however slower in the 195 encapsulated fraction compared to both the free fraction and the neat sample, indicating 196 clearly lower availability of oxygen. These results are in agreement with previous 197 studies on oils microencapsulated in the same matrix as the one used in the present 198 study [5, 14]. It was observed that in these products when an oil sample is stripped of its 199 naturally occurring antioxidants and so unprotected the diffusion of oxygen through the matrix becomes the determining factor of the oxidation rate in the encapsulated fraction.

201 Formation of the main secondary oxidation products of methyl linoleate in the

202 microencapsulated sample was quite different compared to the neat FAME. Both lipid 203 fractions of the powder sample showed significantly much more elevated amounts of 204 secondary products for a given content of hydroperoxydienes (Fig. 3). Whereas in the 205 neat sample the relative contents of keto- and hydroxy- dienes as a whole were not 206 higher than $1.5 \mathrm{wt} \%$ of the total compounds analyzed by HPLC, i.e. hydroperoxy-, keto207 and hydroxy- dienes, the lipid fractions of the microencapsulated FAME showed values 208 between 6 and $31 \mathrm{wt} \%$. In addition, unlike the neat sample and other samples of neat 209 FAME studied at different conditions elsewhere [7, 8], hydroxydienes formed at 210 significantly higher amounts than ketodienes in the microencapsulated FAME.

211 The larger contents of degradation products from hydroperoxides found in the 212 microencapsulated sample can be attributed to the discontinuous nature of oxidation in a 213 product where the lipids constitute a disperse phase [5]. The extracts would come from 214 lipid droplets with very different extents of oxidation. On the one hand, the lipid 215 fraction would be formed from droplets relatively protected by the matrix, in early 216 stages of oxidation and so with hydroperoxides and very low contents of secondary 
217 products and, on the other, from droplets in advanced stages in which hydroperoxides

218 decompose more quickly than are formed generating substantial contents of secondary 219 oxidation products. This hypothesis was supported by the analysis of polymers.

220 Likewise, for a given concentration of hydroperoxides the contents of polymers were 221 also more elevated in the encapsulated lipid fraction than in the neat FAME sample 222 (Fig. 4), indicating formation of advanced oxidation compounds in certain droplets. The 223 free lipid fraction exhibited an intermediate situation between the continuous system 224 and the encapsulated fraction (Fig. 3-4) and therefore also showed lipid droplets oxidizing at different rates. In previous studies, however, the free lipid fraction of dried microencapsulated oils showed an oxidative pattern similar to that of oils in continuous

227 phase $[5,14]$. Unlike the encapsulated fraction, most of the free oil comes from discrete 228 discontinuous deposits localized on the surface of the powder particles, constituting the surface oil $[20,21]$. However, part of the free oil is also formed from droplets localized in the vicinity of the particle surface that are accessible to the extraction solvent. These

231 keep their structure and are completely surrounded by the encapsulation matrix. This 232 more internal subfraction may oxidize following a pattern characteristic of a 233 discontinuous phase.

234 Compared to the free fraction, polymerization in the encapsulated FAME occurred at 235 early stages of oxidation (Fig. 4). This early polymerization is in agreement with results

236 of previous studies [14]. Even though the total content of the oxidation products 237 increased much more quickly in the free fraction of dried microencapsulated oils along 238 storage, polymerization was detected at quite earlier stages in the encapsulated oil. It 239 was suggested that a subfraction of the encapsulated oil was very susceptible to lipid oxidation and oxidized much more quickly than the free oil. 
241 With regard to the higher contents of hydroxy- than keto- dienes found in the lipid 242 extracts, the results suggest that these differences could be related to an effect of the 243 encapsulation matrix, acting as a potent donor of hydrogen or as a reducing agent of

244 hydroperoxides. Due to its emulsifying properties and so its elevated concentration in 245 the interface oil-matrix, it seems reasonable to think that sodium caseinate could be 246 involved in such a hypothetical chemical effect of the encapsulation wall. In this regard, 247 caseins have been reported to show both antioxidant and free radical scavenging 248 activities in liquid systems [22]. Various types of bovine caseins inhibited oxidation of 249 linoleic acid in emulsion. The oxidation was induced with the radical initiator 2,2'250 azobis(2-amidinopropane) (AAPH) and inhibition was measured by oxygen 251 consumption. The authors suggested that caseins are preferred targets for free radical 252 intermediates over the lipid substrate. The same authors found that caseins were also 253 capable of quenching the nitrogen-centered radical 1,1-diphenyl-2-picryl-hydrazyl

254 (DPPH), showing free radical scavenging properties. Hidalgo et al. [23] have also 255 observed radical scavenging activity on DPPH in hydrolysates of bovine sodium 256 caseinate, showing antioxidant properties of its peptides. The amino acids tyrosine, 257 phenylalanine, tryptophan, proline, methionine, lysine and histidine have been reported 258 to be antioxidative [24]. Therefore, there are evidences on the capability of caseins to 259 donate hydrogen radicals. This hypothetical effect of the matrix did not seem to alter the 260 relative distributions of the isomers of hydroperoxydienes (Fig. 1), nor that of their 261 derived compounds, keto- and hydroxy- dienes (not shown). The chromatograms 262 showed a pattern characteristic of uninhibited oxidation. The isomerization of the forms cis,trans or trans,cis to trans,trans was not inhibited by a potent hydrogen donor [25]

264 and the compounds with a trans,trans configuration were somewhat more abundant as a 265 result [7]. 
266 The higher contents of hydroxy- compared to keto- dienes in the microencapsulated

267 FAME could also be explained by a direct reduction of hydroperoxides to hydroxides.

268 In fact, hydroxydienes were detected in both lipid fractions at early stages of oxidation

269 (Fig. 3). In this respect, methionine and cysteine residues in proteins, including casein,

270 have shown peroxide scavenging activities in aqueous systems and it has been

271 suggested that lipid hydroperoxides can be transformed into the corresponding

272 hydroxides through a two-electron reduction [26-29]. In contrast to the hypothetical role

273 of the protein acting as a potent hydrogen donor, formation of hydroxides by direct

274 reduction of hydroperoxides would explain the fact that the geometrical isomers of

275 hydroperoxydienes and those of their derived compounds were those characteristic of

276 uninhibited oxidation. In addition, such formation of hydroxides is not in contrast to the

277 assumption that the larger contents of degradation products from hydroperoxides found

278 in the microencapsulated sample can be attributed to the discontinuous nature of lipid

279 oxidation in these systems. Reduction of hydroperoxides to relatively more stable

280 compounds would not give rise to an increase in the global oxidation rate nor in the

281 formation of compounds of advanced oxidation, i.e. polymers.

\section{Conclusions}

283 The results of this study evidence the importance of applying complementary analytical

284 methods to those assessing the primary oxidation products only to evaluate lipid 285 oxidation in dried microencapsulated lipids or other foods in which the lipids constitute

286 a disperse phase. Substantial formation of secondary oxidation products and even

287 polymerization compounds can occur even when the level of global oxidation is low.

288 The oxidative degradation of certain droplets or minor lipid fractions could help explain

289 the development of rancidity in foods presenting quite low contents of hydroperoxides. 
291 This work was funded by "Ministerio de Economía y Competitividad" through project

292 AGL2013-45110-R, "Junta de Andalucía" through project P09-AGR-4622 and CSIC 293 through a PIE project with reference 201270E134.

294 


\section{References}

296 1. Vega C, Roos YH (2006) Spray-dried dairy and dairy-like emulsions 297 Compositional considerations. J Dairy Sci 89:383-401

2. Gharsallaoui A, Roudaut G, Chambin O, Voilley A, Saurel R (2007) Applications of spray-drying in microencapsulation of food ingredients: An overview. Food Res Int 40:1107-1121

3. Drusch S, Mannino S (2009) Patent-based review on industrial approaches for the microencapsulation of oils rich in polyunsaturated fatty acids. Trends Food Sci Technol 20:237-244

4. Velasco J, Dobarganes MC, Márquez-Ruiz G (2003) Variables affecting lipid oxidation in dried microencapsulated oils. Grasas y Aceites 54:304-314

5. Velasco J, Marmesat S, Dobarganes C, Márquez-Ruiz G (2006) Heterogeneous aspects of lipid oxidation in dried microencapsulated oils. J Agr Food Chem $54: 1722-1729$

6. Hopia A, Huang SH, Frankel EN (1996) Effect of $\alpha$-tocopherol and Trolox on the decomposition of methyl linoleate hydroperoxides. Lipids 31:357-365

7. Morales A, Dobarganes C, Márquez-Ruiz G, Velasco J (2010) Quantitation of hydroperoxy-, keto- and hydroxy-dienes during oxidation of FAMEs from highlinoleic and high-oleic sunflower oils. J Am Oil Chem Soc 87:1271-1279

8. Morales A, Dobarganes C, Márquez-Ruiz G, Velasco J (2012) Formation of hydroperoxy-, keto- and hydroxy-dienes in FAME from oils: influence of temperature and addition of $\alpha$-tocopherol. J Am Oil Chem Soc 89:675-684

9. Morales A, Marmesat S, Dobarganes C, Márquez-Ruiz G, Velasco J (2012)

318 Quantitative analysis of hydroperoxy-, keto- and hydroxy-dienes in refined vegetable oils. J Chromatogr A 1229:190-197 
10. Dobarganes MC, Márquez Ruiz G (2003) Oxidized fats in foods. Curr Opin Clin Nutr Metab Care 6:157-163

11. Morales A, Marmesat S, Dobarganes C, Márquez-Ruiz G, Velasco J (2012) Evaporative light scattering detector in normal-phase high-performance liquid chromatography determination of FAME oxidation products. J Chromatogr A

12. Morales A, Marmesat S, Ruiz-Méndez MV, Márquez-Ruiz G, Velasco J (2014) Formation of oxidation products in vegetable oils analysed as FAME derivatives by HPLC-UV-ELSD. Food Res Int 62:1080-1086

13. Holgado F, Márquez-Ruiz G, Dobarganes C, Velasco J (2013) Influence of homogenisation conditions and drying method on physicochemical properties of dehydrated emulsions containing different solid components. Int J Food Sci

14. Velasco J, Holgado F, Dobarganes C, Márquez-Ruiz G (2009) Influence of relative humidity on oxidation of the free and encapsulated oil fractions in freeze-dried microencapsulated oils. Food Res Int 42:1492-1500

15. Sankarikutty B, Sreekumar MM, Narayanan CS, Mathew AG (1988) Studies on microencapsulation of cardamon oil by spray-drying technique. J Food Sci Technol $25: 352-356$

16. Velasco J, Marmesat S, Holgado F, Márquez-Ruiz G, Dobarganes C (2008) Influence of two lipid extraction procedures on the peroxide value in powdered infant formulas. Eur Food Res Technol 226:1159-1166

17. IUPAC (1992) Standard Methods for the Analysis of Oils, Fats and Derivatives, 7th edn. International Union of Pure and Applied Chemistry, Blackwell Scientific, Oxford, UK 
18. Roos YH (2010) Glass transition temperature and its relevance in food processing. Annu Rev Food Sci Technol 1:469-496

19. Thomas ME, Scher J, Desobry-Banon S, Desobry S (2004). Milk powders ageing: Effect on physical and functional properties. Crit. Rev. Food Sci. Nutr. 44(5):297-

20. Gejl-Hansen F, Flink JM (1977) Freeze-dried carbohydrate containing oil-in-water emulsions: microstructure and fat distribution. J Food Sci 42:1049-1055

21. Drusch S, Berg S (2008) Extractable oil in microcapsules prepared by spray-drying:

26. Sattler W, Christison J, Stocker R (1995) Cholesterylester hydroperoxide reducing activity associated with isolated high- and low-density lipoproteins. Free Radical Biol Med 18:421-429 
27. Garner B, Waldeck AR, Witting PK, Rye KA, Stocker R (1998) Oxidation of high density lipoproteins II. Evidence for direct reduction of lipid hydroperoxides by methionine residues of apolipoproteins AI and AII. J Biol Chem 273:6088-6095

28. Luo D, Smith SW, Anderson BD (2005) Kinetics and mechanism of the reaction of 374 cysteine and hydrogen peroxide in aqueous solution. J Pharm Sci 94:304-316

375 29. Zhou L, Elias RJ (2014) Influence of cysteine and methionine availability on 376 protein peroxide scavenging activity and phenolic stability in emulsions. Food 377 Chem 146:521-530

378 
380 Fig. 1. HPLC chromatograms registered at 234 and $268 \mathrm{~nm}$ of oxidized neat FAME (a)

381 and the free (b) and encapsulated (c) fractions of oxidized microencapsulated FAME.

382 Fig. 2. Formation of hydroperoxy-, keto- and hydroxy- dienes in neat FAME (circles)

383 and the free (squares) and encapsulated (triangles) fractions of microencapsulated

384 FAME. Error bars express standard deviation.

385 Fig. 3. Relationships of keto- and hydroxy- with hydroperoxy- dienes in neat FAME 386 (circles) and the free (squares) and encapsulated (triangles) fractions of 387 microencapsulated FAME. Error bars express standard deviation.

388 Fig. 4. Relationship between polymers and hydroperoxydienes in neat FAME (circles) 389 and the free (squares) and encapsulated (triangles) fractions of microencapsulated 390 FAME. Error bars express standard deviation. Error bars express standard deviation. 

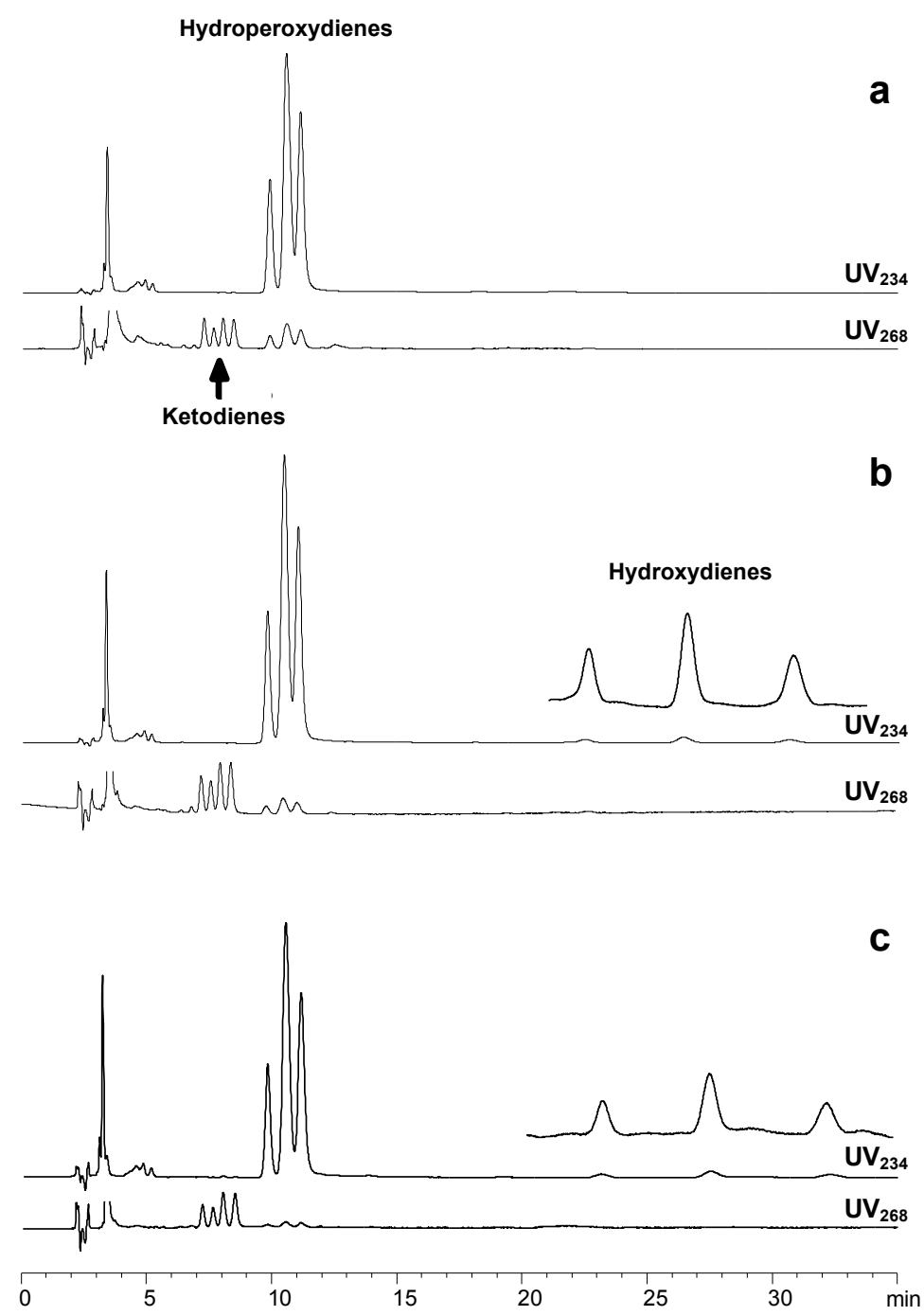

Figure 1 

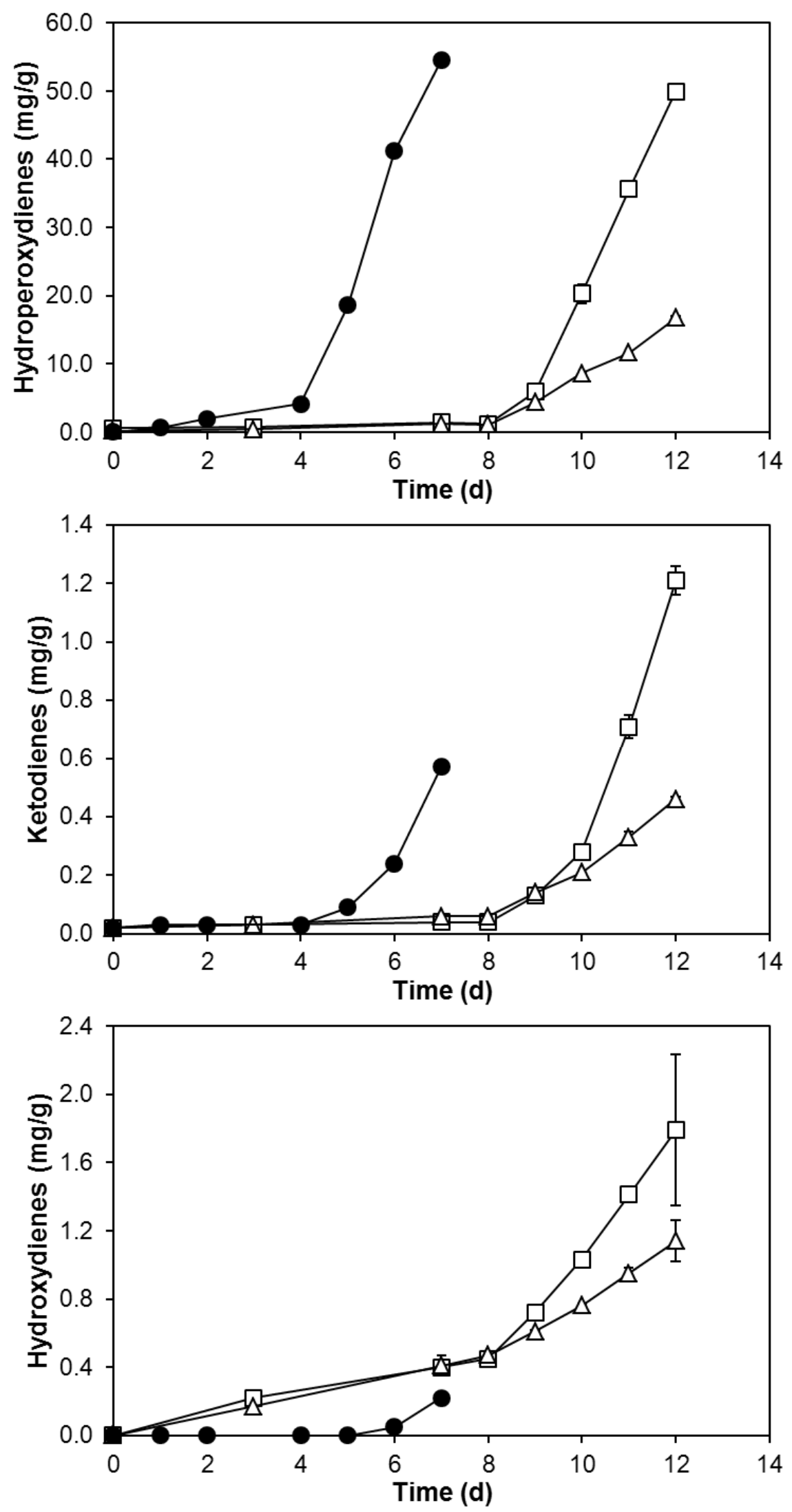

Figure 2 

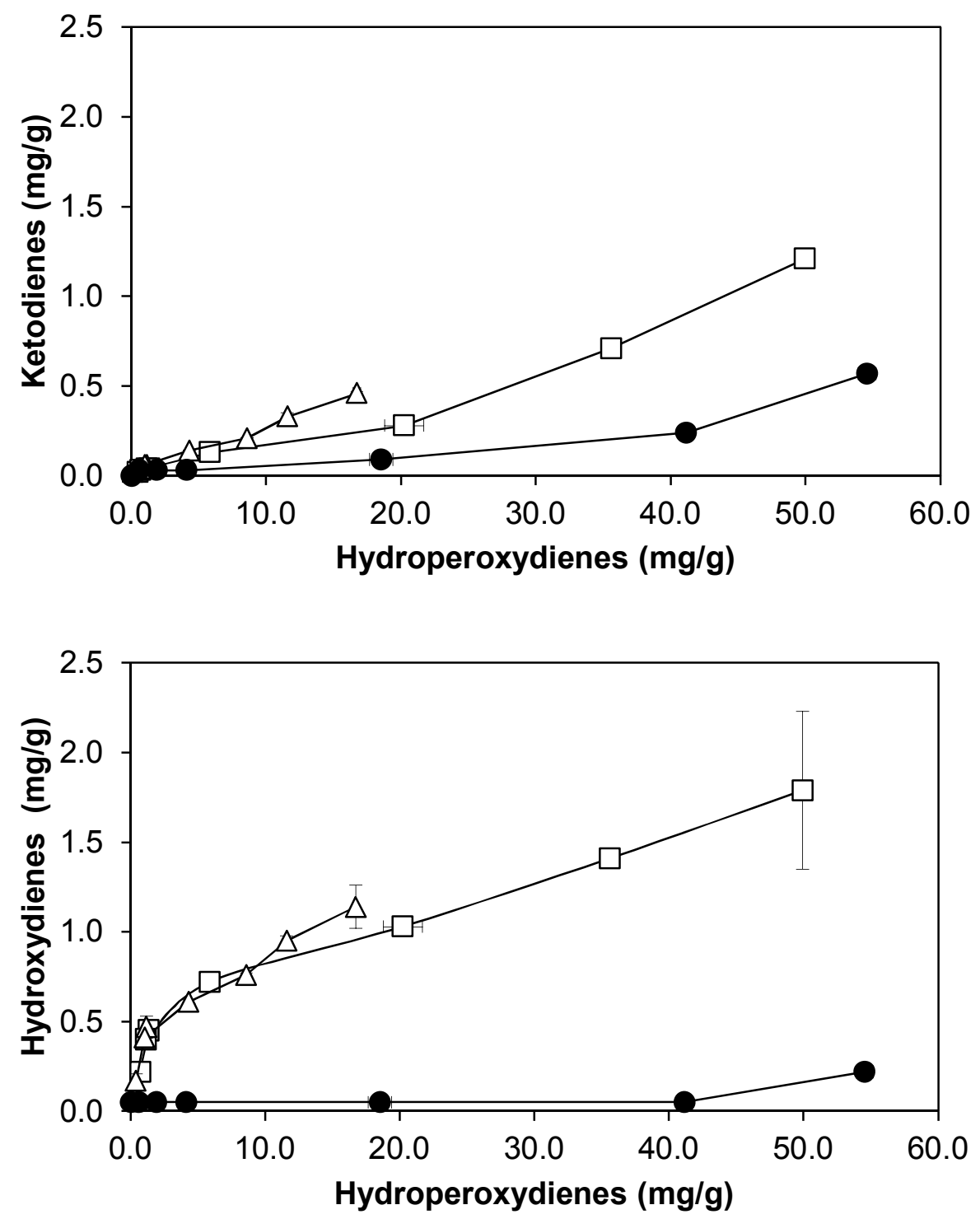

Figure 3 


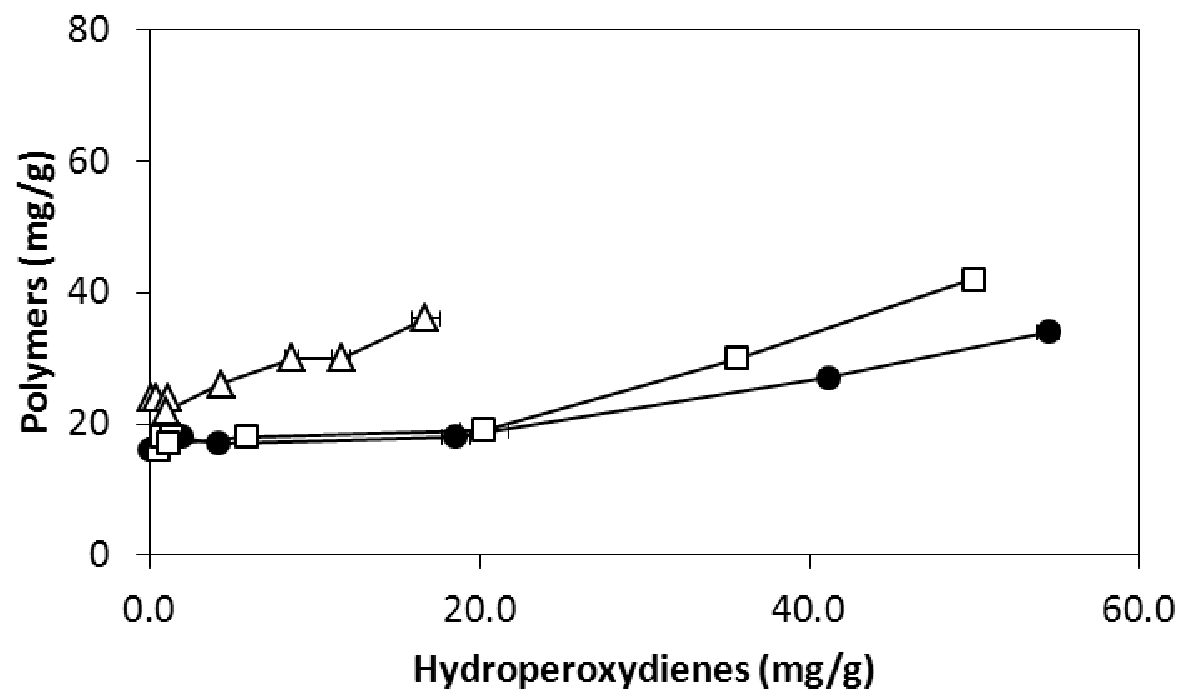

Figure 4 